\title{
Intoxication of epithelial cells by plasmid-encoded toxin requires clathrin-mediated endocytosis
}

\begin{abstract}
Correspondence
Fernando Navarro-García

fnavarro@cell.cinvestav.mx
\end{abstract}

Received 14 February 2007

Revised 1 May 2007

Accepted 14 May 2007

\author{
Fernando Navarro-García, Adrián Canizalez-Roman, Jorge E. Vidal \\ and Ma. Isabel Salazar
} Department of Cell Biology, Centro de Investigación y de Estudios Avanzados
(Cinvestav-Zacatenco), Ap. Postal 14-740, 07000 México, DF, Mexico

\section{INTRODUCTION}

Enteroaggregative Escherichia coli (EAEC) has been associated with persistent infant diarrhoea, especially in developing countries (Bhan et al., 1989; Cravioto et al., 1991). The pathogenesis of EAEC infection is not completely understood (Harrington et al., 2006), although histopathological alterations to the intestinal epithelium from patients and animal models infected with EAEC have been reported (Nataro et al., 1995; Tzipori et al., 1992). Similar histological alterations have been observed in autopsy samples of the ileum from children who had died as a consequence of persistent diarrhoea caused by an EAEC infection (Eslava et al., 1993). We have shown that a $104 \mathrm{kDa}$ EAEC protein, termed Pet (plasmid-encoded toxin) (Eslava et al., 1998), is required for EAEC-induced damage to human intestinal mucosa (Henderson et al., 1999). We have also found that Pet bears nucleotide homology to a class of serine protease autotransporter

Abbreviations: $\mathrm{CHC}$, clathrin heavy chain; $\mathrm{CT}$, cholera toxin; EAEC, enteroaggregative Escherichia coli; FAS, fluorescence actin staining; Pet, plasmid-encoded toxin; siRNA, small interfering RNA; TRITC, tetramethylrhodamine isothiocyanate.

A supplementary figure showing inhibition of CT and transferrin internalization by filipin or cadaverine is available with the online version of this paper. proteins from E. coli and Shigella (Henderson et al., 2004). Pet encompasses the three classical domains (signal sequence, passenger domain and translocation unit) of autotransporters that are needed for its autosecretion (Henderson et al., 2004). Pet also has a conserved serine protease motif responsible for cleaving its target (Canizalez-Roman \& Navarro-García, 2003; Eslava et al., 1998).

Pet appears to be a cytoskeleton-altering toxin, since it induces contraction of the cytoskeleton, loss of actin stress fibres, and release of focal contacts in HEp-2 and HT29/C1 cells, followed by cell rounding and detachment (NavarroGarcía et al., 1999). Pet cytotoxicity and enterotoxicity depend on Pet serine protease activity, since both effects are inhibited by PMSF, and are not induced by Pet S260I, which is mutated in the catalytic serine (Navarro-García et al., 1999). Recently, we have shown that Pet enters the eukaryotic cell by a retrograde transport (Navarro-García et al., 2007), and that this step is required for the induction of the cytotoxic effect (Navarro-García et al., 2001). In addition, we found an intracellular target for Pet: fodrin, which is cleaved by Pet in vivo. The cleavage site is localized within the 11th repetitive unit of fodrin, in the helix $\mathrm{C}$ between $\mathrm{M}_{1198}$ and $\mathrm{V}_{1199}$, which is inside the calmodulinbinding domain. Pet-treated HEp-2 cells have revealed intracellular redistribution of fodrin that leads to 
cytoskeletal damage and cell detachment (CanizalezRoman \& Navarro-García, 2003).

The mechanism for Pet uptake by epithelial cells must be critical since Pet has an intracellular target, which is related to the cytotoxic effect. Additionally, other homologous autotransporters might be using the same uptake mechanism, for instance Sat, EspP (also called PssA) and SigA, from uropathogenic E. coli, enterohaemorrhagic E. coli and Shigella flexneri, respectively (Al-Hasani et al., 2000; Djafari et al., 1997; Maroncle et al., 2006). Here, we show that Pet binds to the cell surface, and is then endocytosed by clathrin-coated vesicles, allowing it to access the eukaryotic cells, and reach its intracellular target.

\section{METHODS}

Antibodies and Pet preparation. Primary antibodies used in this study were: rabbit anti-Pet polyclonal antibody (Navarro-García et al., 1998), goat anti-clathrin polyclonal antibody (Sigma-Aldrich), mouse anti-caveolin monoclonal antibody (clone Z034; Zymed Laboratories), mouse anti-actin monoclonal antibody (a gift from Dr Manuel Hernández, Department of Cell Biology, CINVESTAV-IPN, Mexico), sheep anti-human transferrin (Serotec), and mouse anti-clathrin monoclonal antibody (Santa Cruz Biotechnology). The secondary antibodies used were: Cy5-labelled mouse anti-goat IgG (Jackson ImmunoResearch Laboratories), Cy5labelled goat anti-rabbit IgG, rhodamine- and fluoresceinlabelled goat anti-rabbit polyclonal antibodies, rhodamine-labelled goat anti-mouse polyclonal antibodies, peroxidase-labelled goat antirabbit and rabbit anti-sheep antibodies (all from Zymed Laboratories).

The minimal Pet clone HB101(pCEFN1), described by Eslava et al. (1998), was used to obtain Pet protein (Navarro-García et al., 1999). Briefly, culture supernatants were obtained from HB101(pCEFN1), which was grown in L-broth containing $100 \mu \mathrm{g}$ ampicillin $\mathrm{ml}^{-1}$. The supernatants were filtered through $0.22 \mu \mathrm{m}$ cellulose acetate membrane filters (Corning), concentrated 100 -fold in an ultrafree centrifugal filter device with a $100 \mathrm{kDa}$ cut-off (Millipore), filtersterilized again, and stored at $-20{ }^{\circ} \mathrm{C}$ for up to 3 months (NavarroGarcía et al., 1999).

Cell culture. HEp-2 cells were propagated in humidified $5 \% \mathrm{CO}_{2}-$ $95 \%$ air at $37{ }^{\circ} \mathrm{C}$ in Dulbecco's modified Eagle's medium (DMEM) supplemented with $5 \%$ fetal bovine serum (Hyclone), $1 \%$ non-essential amino acids, $5 \mathrm{mM}$ L-glutamine, penicillin (100 units $\left.\mathrm{ml}^{-1}\right)$, and streptomycin $\left(100 \mu \mathrm{g} \mathrm{ml}^{-1}\right)$. The subcultures were serially propagated after harvesting with $10 \mathrm{mM}$ EDTA and $0.25 \%$ trypsin (Gibco-BRL) in PBS (pH 7.4). For experimental use, subconfluent HEp-2 cells were resuspended in EDTA/trypsin, plated into eight-well LabTek slides (VWR), and allowed to grow to $70 \%$ confluence.

Tissue culture assay. For all experiments, Pet protein was diluted directly into tissue culture medium (without antibiotics or serum), and added to the target cells at a final volume of $250 \mu \mathrm{l}$ per well (eight-well LabTek slides). For control experiments, cholera toxin (CT) and holo-transferrin (Sigma-Aldrich) were used. Following the specified incubation times in humidified atmosphere of $5 \% \mathrm{CO}_{2}-$ $95 \%$ air at $37{ }^{\circ} \mathrm{C}$, the medium was aspirated, cells were washed twice with PBS, and processed for both fluorescence actin staining (FAS) and immunostaining techniques. The cells were fixed with $2 \%$ formalin/PBS, washed, permeabilized by adding $0.2 \%$ Triton X-100/
PBS, stained with $0.05 \mu \mathrm{g} \mathrm{ml}{ }^{-1}$ tetramethylrhodamine isothiocyanate (TRITC)-phalloidin (Sigma Chemical), and incubated with one of the primary antibodies (see antibodies section). The antigen-antibody reaction was developed using one of the fluorescein-, rhodamine- or CY5-labelled secondary antibodies (see Antibodies and Pet preparation). Slides were mounted on Gelvatol (Sigma-Aldrich), covered with a glass cover slide, and examined under a Leica TCS SP2 confocal microscope.

Drug treatments. HEp-2 cells were preincubated for 30 min at $37{ }^{\circ} \mathrm{C}$ in DMEM culture medium containing one of the following inhibitors: filipin $\left(1 \mu \mathrm{g} \mathrm{ml}^{-1}\right)$, monodansylcadaverine $(500 \mu \mathrm{M})$, sucrose $(50 \mathrm{mM})$, or methyl- $\beta$-cyclodextrin $(4 \mathrm{mM})$. All of the inhibitors were obtained from Sigma-Aldrich. After these treatments, Pet was added at $37 \mu \mathrm{g} \mathrm{ml}^{-1}$ for $3 \mathrm{~h}$. Cells were washed three times with PBS, and were prepared for immunostaining, as described above.

Immunoprecipitation assays. Cultured HEp-2 cells in cell culture dishes $(60 \mathrm{~mm} \times 15 \mathrm{~mm})$ were incubated with Pet $\left(37 \mu \mathrm{g} \mathrm{ml}^{-1}\right)$ or transferrin $\left(37 \mu \mathrm{g} \mathrm{ml}^{-1}\right)$ for $8 \mathrm{~min}$ at $37^{\circ} \mathrm{C}$. Cells were washed with cold PBS, resuspended in $1 \mathrm{ml}$ cold lysis buffer [50 mM Tris/ $\mathrm{HCl}$, $150 \mathrm{mM} \mathrm{NaCl}, \mathrm{pH} 7.5,1 \%$ Nonident P-40, $0.5 \%$ sodium deoxycholate, and the protease inhibitors (Complete; Roche Diagnostics)], and detached by using a cell scraper. Cells were placed in a $1.5 \mathrm{ml}$ microtube, and lysed by passing them through a syringe with a 27 gauge needle. Lysed cells $(500 \mu \mathrm{g})$ were centrifuged at $12000 \mathrm{~g}$ for $10 \mathrm{~min}$ at $4{ }^{\circ} \mathrm{C}$, and the supernatant was placed in a clean $1.5 \mathrm{ml}$ microtube. To perform the immunoprecipitation assay, the supernatant was incubated with either anti-clathrin $(5 \mu \mathrm{g})$ or anti-caveolin $(5 \mu \mathrm{g})$, with slight agitation for $3 \mathrm{~h}$, at $4{ }^{\circ} \mathrm{C}$. Then, $5 \mu \mathrm{l}$ protein $\mathrm{A}$ agarose suspension (Roche Diagnostics) was added, followed by incubation for $3 \mathrm{~h}$ at $4{ }^{\circ} \mathrm{C}$. The complexes were collected by centrifugation at $12000 \mathrm{~g}$ for $20 \mathrm{~s}$, and the supernatant was removed. The pellet was washed five times with PBS and cold Complete protease inhibitors. The agarose pellet was resuspended in $2 \times$ gelloading buffer, and the samples were boiled for $5 \mathrm{~min}$. The immunocomplexes were analysed by SDS-PAGE. The protein bands obtained were transferred to nitrocellulose membranes (Towbin et al., 1979), and the membranes were probed with anti-Pet or antitransferrin antibodies. The antigen-antibody reaction was visualized using horseradish-peroxidase-labelled goat anti-rabbit IgG, and developed using a Western blotting chemiluminescence reagent (Luminol; Santa Cruz Biotechnology).

RNA interference. Subconfluent cultures (approx. $70-80 \%$ ) of HEp-2 cells in $35 \mathrm{~mm}$ plates were transfected twice for $5 \mathrm{~h}$ with a mixture containing $80 \mathrm{pmol}$ synthetic double-stranded small interfering RNA (siRNA) for clathrin heavy chain (CHC) or caveolin-1 (sc-35067 or sc-29241, respectively; Santa Cruz Biotechnology) and $5 \mu$ lipofectamine 2000 (Invitrogen), in a total volume of $1 \mathrm{ml}$ DMEM, without either antibiotics or serum. The interval between both siRNA transfections was $72 \mathrm{~h}$. One day after the second siRNA transfection, transfected cells and untransfected controls were treated with the Pet for either $30 \mathrm{~min}$ and $1 \mathrm{~h}$, rinsed extensively with PBS after treatment, and collected in lysis buffer using a cell scraper. Relative $\mathrm{CHC}$ and actin levels were analysed by immunoblot in $60 \mu \mathrm{g}$ total protein, using the ECL Western blotting analysis system (Amersham). The resulting autoradiography was scanned and quantified with the Sigma Gel Analysis Software, version 1.0 (Jandel Corporation), to determine intensity. Additionally, transfected cells and untransfected controls were grown in an eightwell Lab-Tek chamber slide, treated with Pet for one of two different time periods ( 2 and $3 \mathrm{~h}$ ), immunostained with the appropriate antibodies, and examined by using confocal microscopy (Leica TCS SP2). 

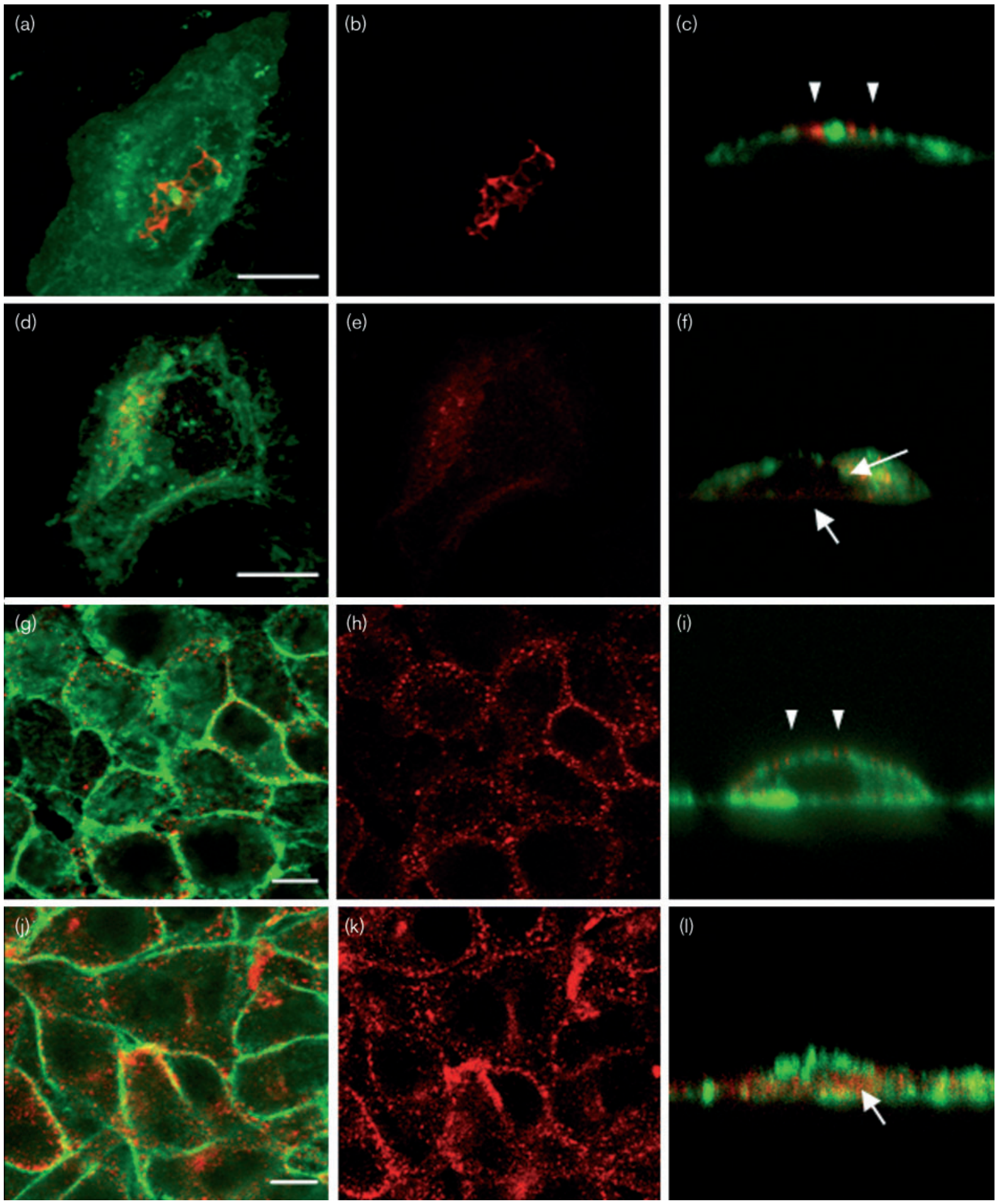

Fig. 1. Detection of Pet on the membrane of HEp-2 cells. Cells were incubated with either Pet $\left(37 \mu \mathrm{g} \mathrm{ml}{ }^{-1}\right)$ or transferrin $\left(37 \mu \mathrm{g} \mathrm{ml}^{-1}\right)$ for $30 \mathrm{~min}$ at $4{ }^{\circ} \mathrm{C}$ or $37^{\circ} \mathrm{C}$. After incubation, cells were fixed, permeabilized, and stained with Ricinus communis agglutinin coupled to fluorescein (green), and with anti-Pet or anti-transferrin antibodies, and a secondary rhodamine-labelled anti-rabbit antibody (red). Slides were observed by confocal microscopy. Cells were treated with Pet for 30 min at $4{ }^{\circ} \mathrm{C}$ (a) or $37{ }^{\circ} \mathrm{C}(\mathrm{d})$. (b, e) Horizontal optical sections, and (c, f) vertical optical sections, of the same cells shown in (a) and (d), respectively. Cells were exposed to transferrin for $30 \mathrm{~min}$ at $4{ }^{\circ} \mathrm{C}(\mathrm{g})$ or at $37{ }^{\circ} \mathrm{C}(\mathrm{j})$. (h, k) Horizontal optical sections, and (i, l) vertical optical sections, of the same cells shown in $(\mathrm{g})$ and $(\mathrm{j})$, respectively. Arrowheads point to Pet on the cell surface, and arrows point to Pet inside the cells. Bars, $20 \mu \mathrm{m}$. 
Projection $(x-y)$

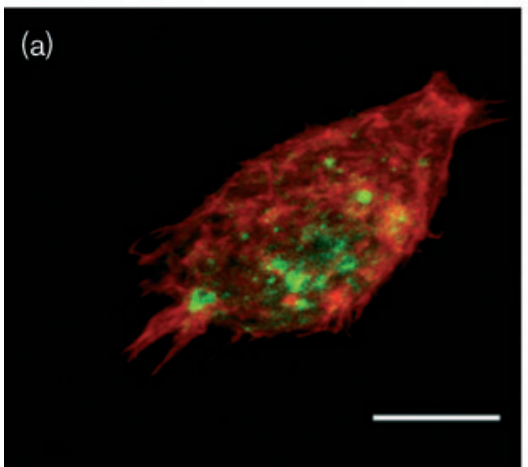

(d)
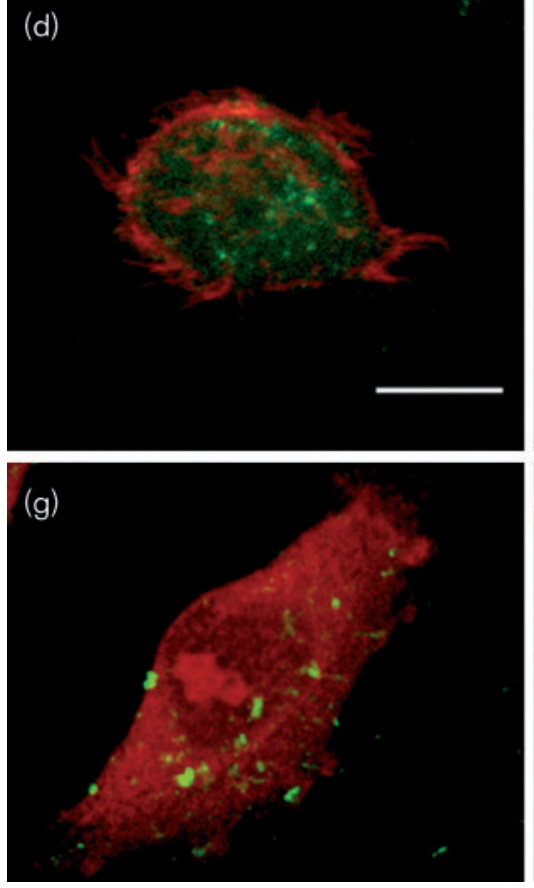

Middle section $(x-y)$

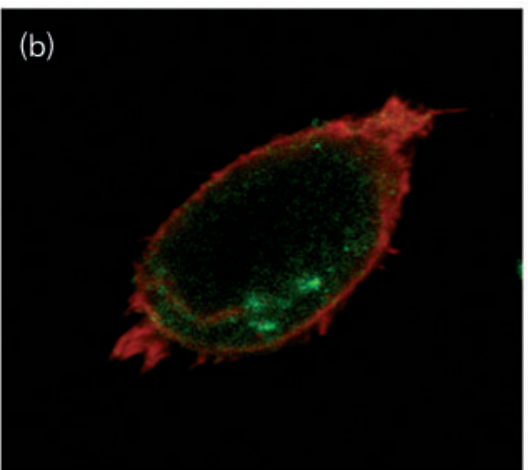

(e)

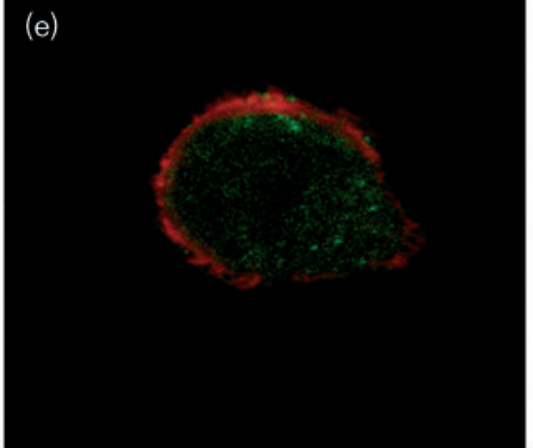

(h)

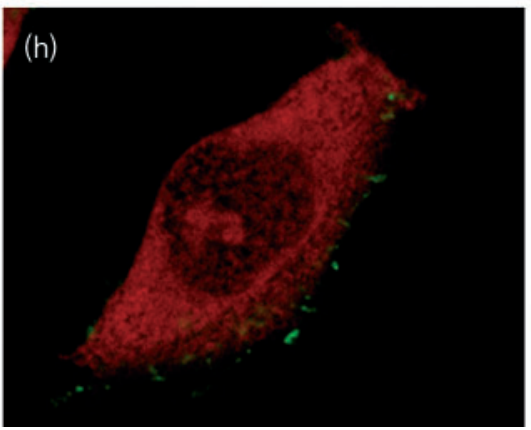

Vertical section $(x-z)$
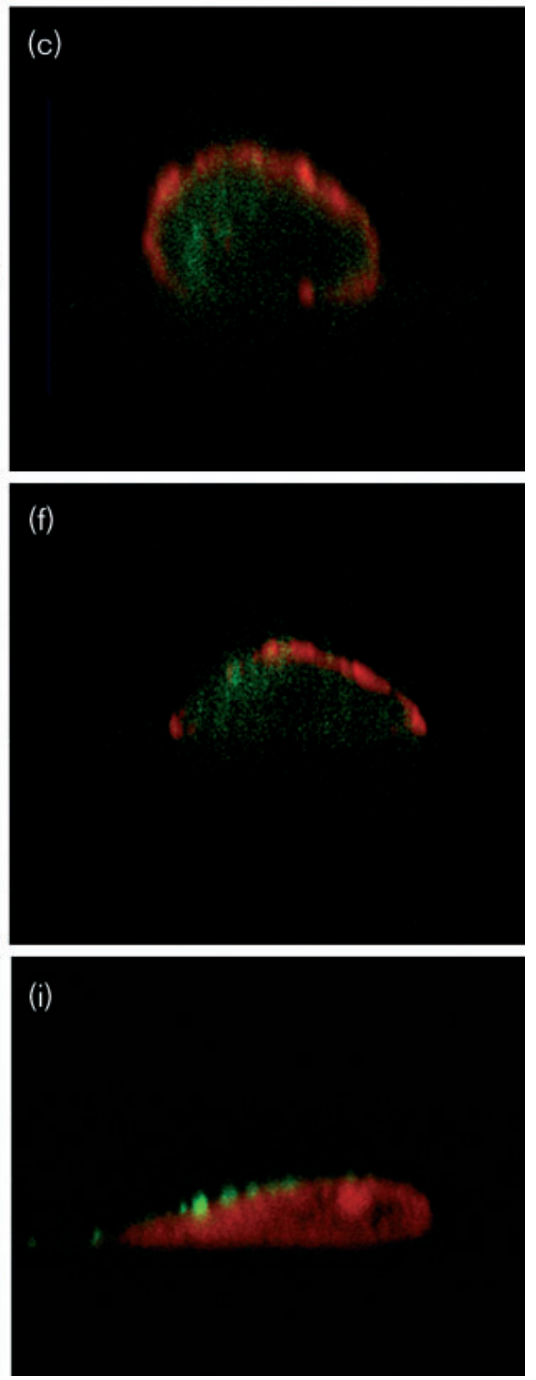

Fig. 2. Effects of endocytosis inhibitors on Pet internalization. HEp-2 cells were preincubated for 30 min with drugs that inhibit the endocytic process. After incubation, cells were treated with Pet $\left(37 \mu \mathrm{g} \mathrm{ml}^{-1}\right)$ for $3 \mathrm{~h}$. The cells were fixed, permeabilized, and stained with rhodamine-phalloidin (red) and anti-Pet antibodies, followed by a secondary fluorescein-labelled goat antirabbit antibody (green). Slides were observed by using confocal microscopy. (a) Cells treated with Pet only. (d) Filipinpreincubated cells treated with Pet. (g) Monodansylcadaverine-preincubated cells treated with Pet. (b, e, h) Horizontal optical sections, and (c, f, i) vertical optical sections, of the same cells shown in (a), (d) and (g), respectively.

\section{RESULTS}

\section{Interaction of Pet with the membrane surface of epithelial cells}

Since Pet is efficiently internalized (Navarro-García et al., 2001), Pet binding to the membrane surface was determined by incubating cells at $4{ }^{\circ} \mathrm{C}$, and using transferrin as a ligand-positive control. HEp-2 cells were incubated with Pet $(355 \mathrm{nM})$ for $30 \mathrm{~min}$. Pet binding to the membrane surface was detected by using anti-Pet antibodies and a secondary TRITC-labelled anti-rabbit antibody, whereas the cell surface was stained with Ricinus communis agglutinin coupled to fluorescein. In cells kept at $4{ }^{\circ} \mathrm{C}$, Pet was localized as red fluorescence marks on the cell surface (Fig. 1b), which, depending on the optical confocal plane, could be observed on the apical surface of the cell (Fig. 1a). In addition, a vertical section clearly showed that Pet was not found inside the cell, but only on the cell surface (Fig. 1c). However, when cells were treated with Pet, under the same conditions, but at $37{ }^{\circ} \mathrm{C}$, Pet was localized inside the cells as punctate red fluorescence marking structures, resembling organelles (Fig. 1d, e). A vertical optical section confirmed that the Pet was inside the 
Surface
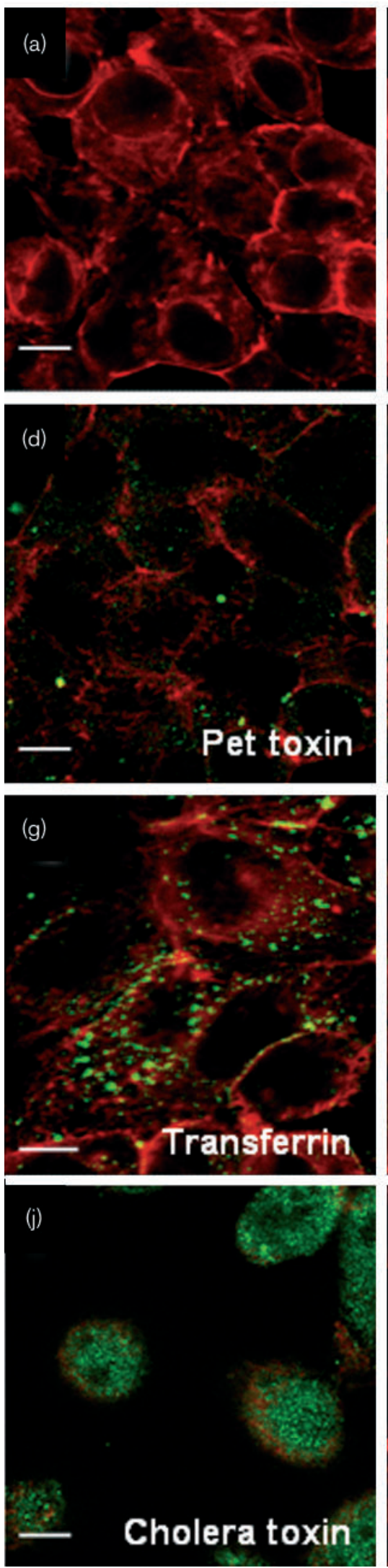

Middle
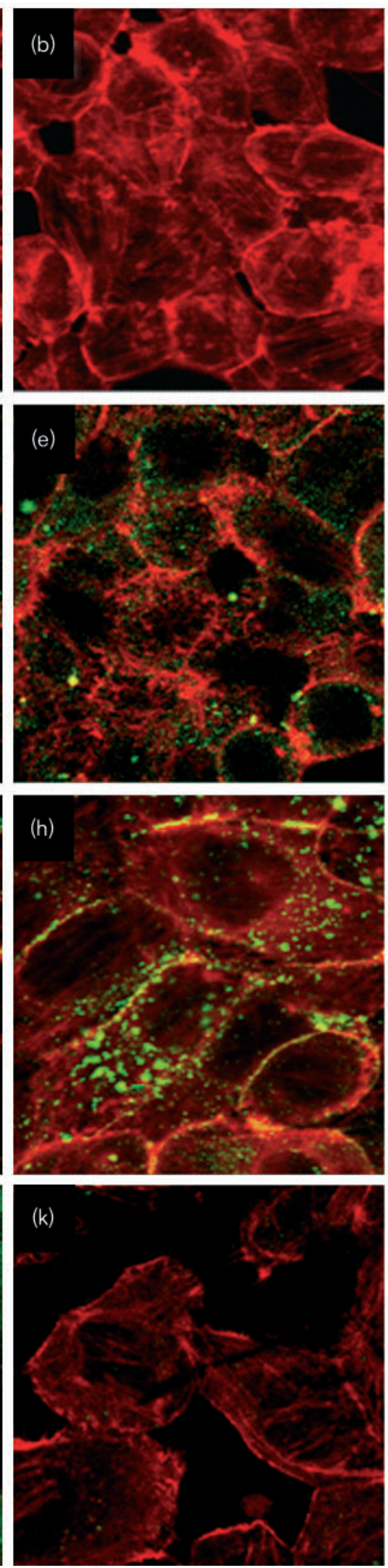

Projection
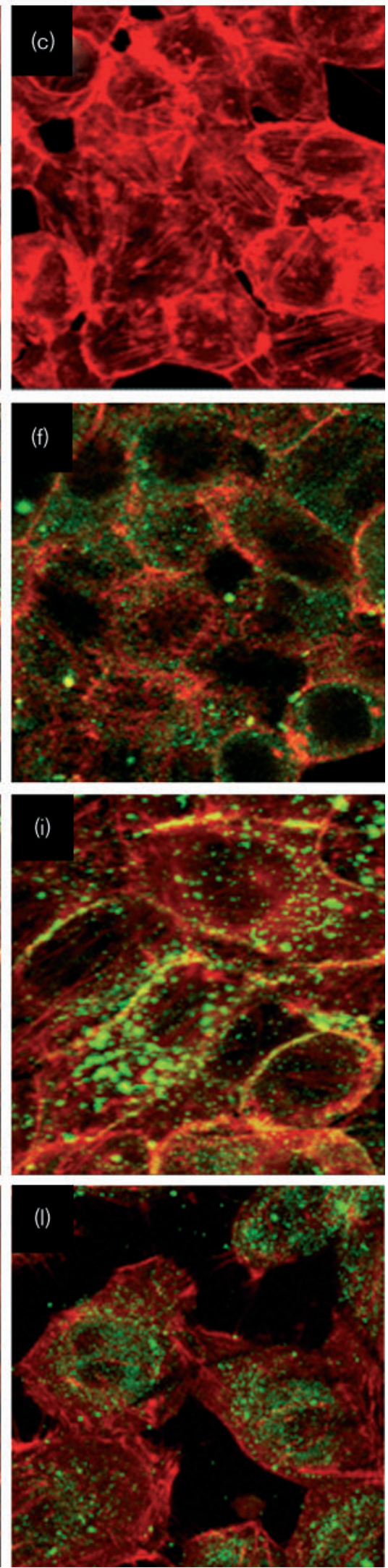
Fig. 3. Pet internalization is not inhibited by methyl- $\beta$-cyclodextrin. Cells were incubated with methyl- $\beta$-cyclodextrin ( $4 \mathrm{mM}$ ) for $60 \mathrm{~min}$ at $37{ }^{\circ} \mathrm{C}$, and then treated with Pet $\left(37 \mu \mathrm{g} \mathrm{ml}^{-1}\right)$, transferrin $\left(37 \mu \mathrm{g} \mathrm{ml}^{-1}\right)$ or CT $\left(0.5 \mu \mathrm{g} \mathrm{ml}^{-1}\right)$ for $1 \mathrm{~h}$. Cells were fixed, permeabilized, stained with rhodamine-phalloidin (red) and anti-Pet, anti-transferrin or anti-CT antibodies, followed by an appropriate secondary fluorescein-labelled antibody (green). (a) Surface and (b) middle sections, and (c) projection, of cells incubated with methyl- $\beta$-cyclodextrin only. (d, e, f) Surface and middle sections, and projection, of drug-pretreated cells incubated with Pet, $(\mathrm{g}, \mathrm{h}, \mathrm{i})$ transferrin, or $(\mathrm{j}, \mathrm{k}, \mathrm{l}) \mathrm{CT}$, respectively. Bars, $20 \mu \mathrm{m}$.

cells (Fig. 1f). These results were similar to those observed with a well known cell-binding protein, transferrin: at $4{ }^{\circ} \mathrm{C}$, transferrin was localized on the cell surface (Fig. $1 \mathrm{~g}, \mathrm{~h}$ ), exclusively on the cell membrane, as detected in vertical section (Fig. 1i); however, in cells incubated at $37{ }^{\circ} \mathrm{C}$, transferrin was localized inside the cells (Fig. $1 \mathrm{j}, \mathrm{k}$ ), as confirmed in a vertical section (Fig. 11). Together, these data indicate that Pet is bound to the cell surface before its internalization, suggesting a receptor-mediated endocytosis.

\section{Pet uptake is blocked by drugs affecting clathrin- mediated endocytosis}

To investigate the possible endocytosis pathways involved in Pet uptake by epithelial cells, we used inhibitors of protein internalization that targeted two main mechanisms: caveolin- and clathrin-mediated endocytosis. Filipin-pretreated HEp-2 cells (to inhibit caveolae vesicle formation) were incubated with Pet for $3 \mathrm{~h}$, and then stained by using anti-Pet antibodies and a secondary FITC-labelled goat anti-rabbit antibody (green). Actin cytoskeleton was stained with rhodamine-phalloidin (red). In these filipinpretreated cells, Pet was detected as diffuse fluorescent marks along the cells (Fig. 2d). Specifically, Pet was localized inside the cells, as revealed by means of a middle optical section (Fig. 2e, section 6 of 12) or a vertical optical section (Fig. 2f, $x-z$ plane), correlating with the actin cytoskeleton disruption and cell rounding. This Pet internalization distribution pattern and actin cytoskeleton disruption was similar to that observed in cells treated with Pet, without filipin pretreatment (Fig. 3a-c). As expected, filipin effectively blocked CT internalization,
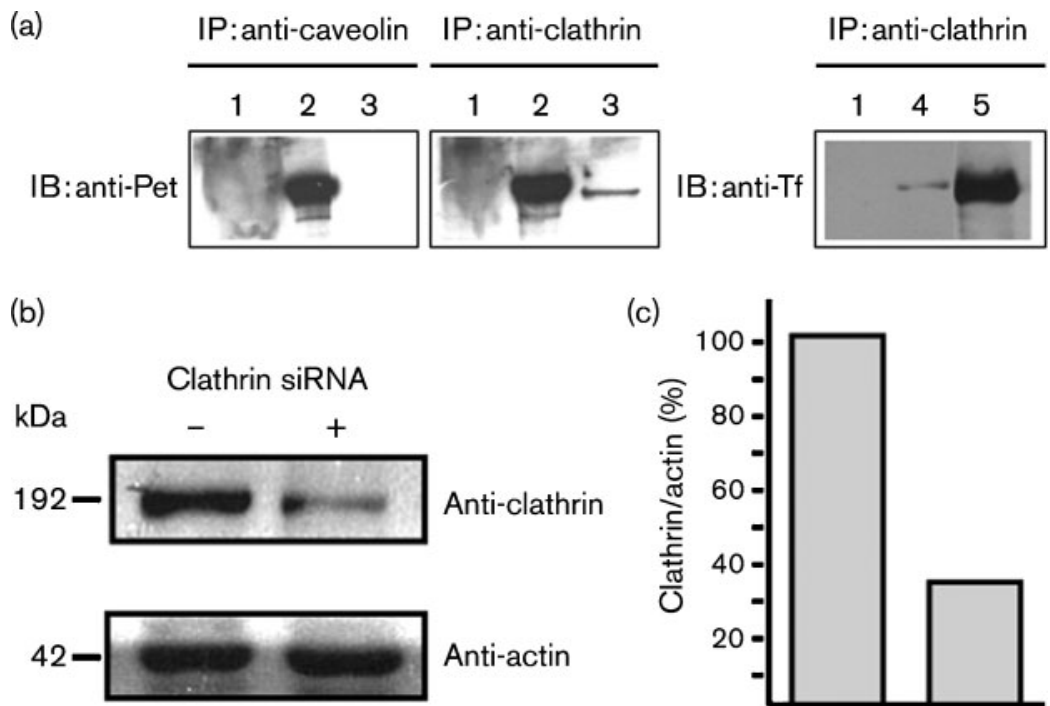

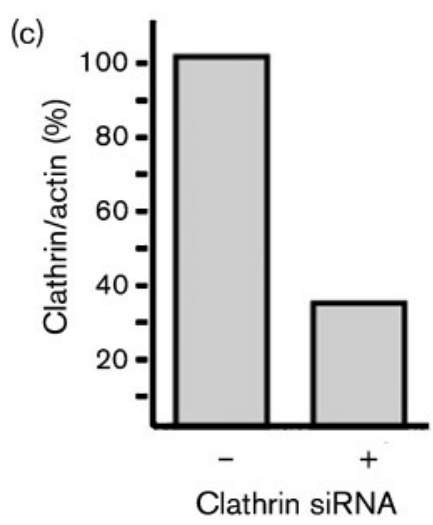

Fig. 4. Co-immunoprecipitation of Pet and clathrin, and knock out of clathrin by siRNA. (a) Immunoprecipitation (IP) and immunoblotting (IB) of Pet by using anti-clathrin antibodies. Cells were treated with Pet $\left(37 \mu \mathrm{g} \mathrm{ml}^{-1}\right)$ or transferrin ( $\mathrm{Tf} ; 37 \mathrm{~g} \mathrm{ml}^{-1}$ ) for $8 \mathrm{~min}$, then lysed, and the supernatant was immunoprecipitated with anti-caveolin or anti-clathrin antibodies. Immunoprecipitates were resolved by PAGE-SDS, and transferred to nitrocellulose membranes. Pet or transferrin in the immunoprecipitates was detected by using anti-Pet or anti-transferrin antibodies, followed by secondary peroxidase-labelled goat anti-rabbit or rabbit anti-sheep antibodies. Lanes: 1, untreated cells; 2, $1 \mu \mathrm{g}$ Pet; 3, Pet-treated cells; 4, Tf-exposed cells; 5, $0.5 \mu \mathrm{g}$ Tf. (b, c) Knock out of $\mathrm{CHC}$ expression by using siRNA. HEp-2 cells were transfected twice with $\mathrm{CHC}$ siRNA or control siRNA (caveolin-1 siRNA), as described in Methods. One day after the second siRNA transfection, cells were lysed using a buffer containing saponin $0.02 \%$, and the proteins from the supernatants were separated by SDS-PAGE, and transferred to nitrocellulose membranes (Tebar et al., 1999). (b) The proteins were detected with anticlathrin or anti-actin. (c) The protein bands detected with the antibodies were quantified by densitometry. The figure shows representative experiments $(n=3)$. 


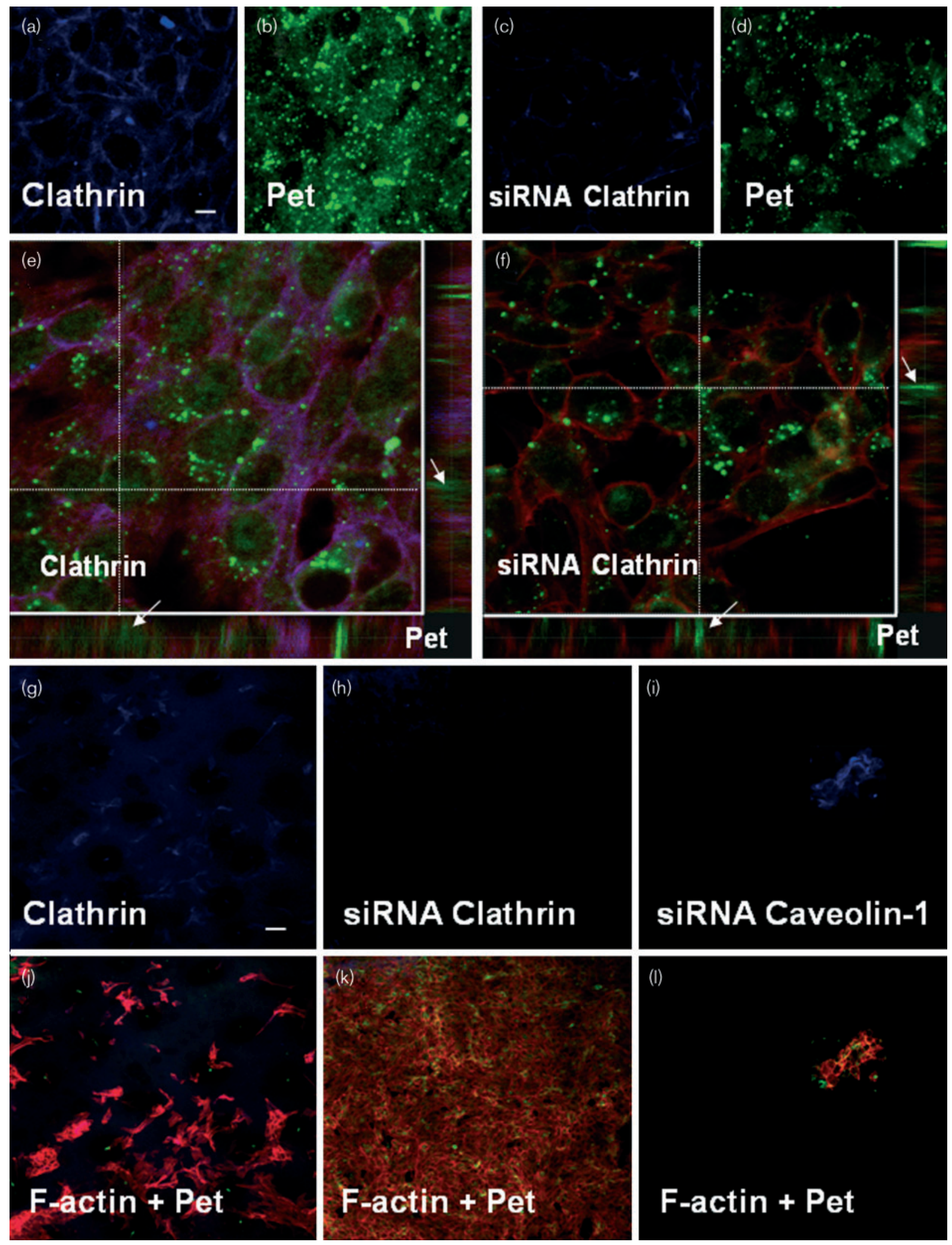


Fig. 5. Knock out of clathrin, but not caveolin-1, abolished Pet internalization, and prevented Pet-induced cytotoxicity. HEp-2 cells were transfected twice with CHC siRNA or control siRNA (caveolin-1 siRNA), as described in Methods. One day after the second siRNA transfection, cells were treated with Pet $\left(37 \mu \mathrm{g} \mathrm{ml}^{-1}\right)$ for (i) $2 \mathrm{~h}$, (ii) $3 \mathrm{~h}$, or (iii) left untreated. Untransfected cells were used as positive controls. Cells were fixed, permeabilized, stained with rhodamine-phalloidin (red), and immunostained with anti-Pet and anti-clathrin antibodies followed by secondary fluorescein-labelled goat anti-rabbit (green) and Cy5-labelled mouse anti-goat (blue) antibodies. (a-f) Pet internalization in clathrin-siRNA-transfected cells. (a, b, e) Untransfected cells treated with Pet; (c, d, f) CHC-siRNA-transfected cells treated with Pet; bar, $20 \mu \mathrm{m}$. (e, f) Middle sections showing vertical $x-z$ and $y-z$ planes in bottom and right margins, respectively (planes are indicated by the dotted lines). Arrows point to Pet inside the cells. (g-l) Pet cytotoxicity in clathrin-siRNA-transfected cells. (g, j) Untransfected cells treated with Pet; (h, k) CHC-siRNAtransfected cells treated with Pet; $(i, l)$ caveolin-1-siRNA-transfected cells treated with Pet; bar, $80 \mu \mathrm{m}$.

which was used as a positive control, and the toxin was localized outside the cells, as detected in a surface section (Supplementary Fig. S1a, available with the online version of this paper), and confirmed in a vertical section (Supplementary Fig. S1b). These data suggest that Pet internalization is not affected by blocking caveolindependent endocytosis.

In contrast, in monodansylcadaverine-pretreated cells (to inhibit clathrin-dependent endocytosis), we observed Pet as fluorescent aggregates along the cells (Fig. 2g). These fluorescent aggregates were not localized inside the cells, as revealed by analysing a middle optical section (Fig. $2 \mathrm{~h}$ ). Furthermore, when these cells were analysed in the $x-z$ plane, Pet was found only on the cell surface (Fig. 2i). As expected, these results were similar to those observed when transferrin uptake was blocked by monodansylcadaverine: transferrin was localized on the cell surface as detected in surface sections (Supplementary Fig. S1c) and confirmed in a vertical section (Supplementary Fig. S1d). Similar data were obtained by using sucrose (data not shown).

Since Pet uptake, like transferrin uptake, occurs by clathrin-dependent endocytosis, its internalization must be unaffected by methyl- $\beta$-cyclodextrin because depletion of cholesterol affects all the clathrin-independent pathways. Indeed, in methyl- $\beta$-cyclodextrin-pretreated cells (Fig. 3ac), both Pet (Fig. 3d-f) and transferrin (Fig. 3g-i) were internalized by these cells, as detected in middle sections (Fig. 3e, h, respectively). However, CT internalization was blocked by methyl- $\beta$-cyclodextrin (Fig. $3 j-1$ ), and the toxin was not detected in the cytoplasm in a middle section (Fig. 3k). Together, these data indicate that Pet uptake occurs through clathrin-dependent endocytosis.

\section{Pet interacts with clathrin, and it is required for Pet endocytosis}

To determine if Pet is included in the endocytic complex of the clathrin-coated pit instead of caveolae, we performed co-immunoprecipitation assays. Pet-treated HEp-2 cells were lysed, and the supernatant was immunoprecipitated with either anti-clathrin or anti-caveolin-1 antibodies. Pet was detected in immunoprecipitates from anti-clathrin antibodies by immunoblot using anti-Pet antibodies, whereas Pet was not detected in immunoprecipitates from anti-caveolin antibodies (Fig. 4a); these results were similar to the result observed in untreated cells (Fig. 4a). Results similar to those for Pet were found when transferrin was used as a positive control. In transferrin-exposed cells immunoprecipitated with anti-clathrin antibodies, transferrin was detected by immunoblot using anti-transferrin (Fig. 4a). These results confirmed those obtained with monodansylcadaverine and sucrose, indicating that Pet uptake occurs through clathrin-dependent endocytosis.

As a final approach to corroborate that Pet entry specifically requires an active pathway of clathrin-mediated endocytosis; we knocked out the CHC using siRNA technology (Fig. 4b). Following two successive transfections of siRNA, CHC levels were downregulated by approximately $70 \%$, as compared with untransfected cells (Fig. 4c). HEp-2 cells treated with or without CHC siRNA were then incubated with Pet, and internalization was analysed by confocal microscopy to discriminate between clathrin-silenced cells and untransfected cells. Thus, the HEp-2 cells were triple stained: actin cytoskeleton was stained with rhodamine-phalloidin (red), Pet internalization was detected by using anti-Pet antibodies (green), and clathrin-silenced cells were identified as cells not immunostained with the anti-clathrin antibodies (blue). In normal HEp-2 cells (without siRNA and Pet treatments) it was possible to detect clathrin and the actin cytoskeleton, but not Pet, as expected (data not shown). However, at $2 \mathrm{~h}$ of treatment with Pet, clathrin was detected, as expected (Fig. 5a), and the toxin was detected inside the cells, as well as bound to the cell surface (Fig. 5b, e). Further confocal microscopy analysis of middle sections, in combination with vertical $x-y$ and $y-z$ planes (the planes were obtained as indicated by the dotted lines), showed that indeed Pet was inside the cells (Fig. 5e). On the other hand, in clathrin-silenced cells without Pet treatment, the anticlathrin antibody was unable to detect clathrin, and only the actin cytoskeleton was detected (data not shown). Interestingly, in clathrin-silenced cells treated with Pet (Fig. 5c), Pet was found in lesser amounts, and bound to the cell surface, forming large aggregates (Fig. 5d), but not inside the cells (Fig. 5f), as further shown by confocal microscopy analysis, using the middle section in combination with vertical $x-y$ and $y-z$ planes (as indicated above) to detect Pet (Fig. 5f). These data indicate that Pet internalization is strongly inhibited in CHC siRNAtransfected cells. 
Since some toxins can be internalized by alternative pathways, we also knocked out caveolin expression by using caveolin-1 siRNA. Following two successive transfections of siRNA, caveolin levels were also downregulated to a value that was approximately $30 \%$ of that for the controls (data not shown). As in the clathrin-silenced cells, HEp-2 cells transfected with or without caveolin siRNA were then treated with Pet, and its internalization was analysed by confocal microscopy to discriminate between the caveolinsilenced cells and the untransfected cells. Unlike clathrinsilenced cells, Pet internalization was not inhibited in caveolin siRNA-treated cells (data not shown, and see Fig. 5i, l).

Another way to further test the role of clathrin-mediated endocytosis during Pet internalization was to determine the cytotoxic effects induced by the toxin after $3 \mathrm{~h}$ incubation. Normal HEp-2 cells, clathrin-silenced cells and caveolin-silenced cells were treated with Pet for $3 \mathrm{~h}$, triple stained using the method described above, and then analysed by confocal microscopy. In normal HEp-2 cells treated with Pet, clathrin was detected in the cells (Fig. 5g), and the cell monolayer lost its confluency due to Pet toxicity, as detected by staining the actin cytoskeleton (Fig. 5j). However, in CHC siRNA-treated cells, clathrin was not detected by anti-clathrin antibodies (Fig. 5h), and Pet was unable to cause the cytotoxic effect, and the cell monolayer kept its confluency, even though some Pet was detected on the cell monolayer (Fig. 5k). Interestingly, in caveolin-siRNA-transfected cells, Pet caused a stronger cell detachment (Fig. 5i, 1) than in normal HEp-2 cells treated with Pet (Fig. 5j), and it was possible to find only those cells that were not transfected by the siRNA, which were detected by the anti-caveolin antibody (Fig. 5l). Thus, it is clear that the cytotoxic effect induced by Pet requires clathrin-mediated endocytosis; although some Pet might enter the cells by caveolae vesicles, this has no impact on the cytotoxic effect induced by Pet, and a lack of caveolin expression enhances the cytotoxic effect.

\section{DISCUSSION}

The aim of this work was to identify the mechanism of Pet uptake by epithelial cells. Here we show that Pet is endocytosed by clathrin-coated vesicles after binding to an unknown receptor on the cell membrane, and this is being further studied in our laboratory. We have recently published that, after Pet uptake in epithelial cells, it follows a retrograde transport from the early endosomes to the Golgi apparatus, and from the Golgi apparatus to the ER, to be translocated to the cytosol by the Sec61p translocon (Navarro-García et al., 2007). Once in the cytosol, Pet reaches its intracellular target(s), which is proteolytically degraded, leading to cytoskeleton disruption (CanizalezRoman \& Navarro-García, 2003). Fodrin degradation correlates with cell damage caused by Pet, including actin cytoskeleton retraction, loss of the stress fibres, cell rounding with membrane blebs, and cell detachment from the substrate (Canizalez-Roman \& Navarro-García, 2003; Navarro-García et al., 1999).

Endocytosis of proteins by cells can be achieved through various mechanisms (Conner \& Schmid, 2003): clathrindependent (Mellman, 1996); clathrin-independent (Lamaze \& Schmid, 1995), which was firstly described for bacterial toxins (Moya et al., 1985); caveolae vesicles, by means of cholesterol- and glycolipid-rich domains (Simons \& Ikonen, 1997); and, finally, macropinocytosis, which depends on membrane ruffling (Steinman \& Swanson, 1995). By using drugs that inhibit endocytosis through either caveolae or clathrin vesicles, we found that Pet is endocytosed by clathrin-coated vesicles. Bacterial toxins are endocytosed mainly through clathrin-coated vesicles. Among these toxins endocytosed this way are diphtheria toxin (Moya et al., 1985), Pseudomonas exotoxin A (Morris et al., 1983), Shiga toxin (Sandvig et al., 1989), and CT; the latter is partially endocytosed by this pathway, as well as being internalized through a caveolae-dependent mechanism (Torgersen et al., 2001). Pet internalization by clathrin-coated vesicles was found to be the essential mechanism, since two reagents (monodansylcadaverine and sucrose) for blocking this pathway totally inhibited Pet internalization. Drugs for blocking endocytosis through the caveolae mechanism (filipin and methyl- $\beta$-cyclodextrin) were unable to inhibit Pet internalization, and thereby the effects on the cytoskeleton. These two endocytosis pathways were compared with those used by transferrin and CT, which constituted the positive controls for the clathrin-mediated and the caveolae pathway, respectively. Monodansylcadaverine has been used to block toxin entry by clathrin-mediated endocytosis; examples include Pseudomonas exotoxin A (Saelinger et al., 1985) and shiga-like toxin (verotoxin) (Khine \& Lingwood, 1994). Moreover, a study of CT internalization using drugs similar to those used in our study showed that even though CT is associated with detergent-insoluble cholesterol-enriched domains (rafts) at the cell surface of cultured hippocampal neurons, it is internalized via a raft-independent mechanism. The cholesterol-binding agents filipin and methyl$\beta$-cyclodextrin have no effect on the rate of CT or transferrin receptor internalization (Shogomori \& Futerman, 2001). These two drugs have been used exhaustively to characterize alternative pathways for CT internalization (Torgersen et al., 2001).

Furthermore, like transferrin, Pet interacts with clathrin during endocytosis in Pet-treated cells, since it was possible to immunoprecipitate Pet by using anti-clathrin antibodies. These data suggest that the mechanism of Pet uptake in epithelial cells seems to be similar to the mechanism used by diphtheria toxin, Pseudomonas exotoxin A and Shiga toxin (Falnes \& Sandvig, 2000).

Although inhibitors for clathrin- and caveolae-mediated endocytosis have been used exhaustively in endocytosis studies, and we used the appropriate controls, such as transferrin and $\mathrm{CT}$, we decided to verify our finding by 
depleting $\mathrm{CHC}$, as well as caveolin-1, by using siRNAs. We used CHC siRNA as a control siRNA for caveolin-1, and vice versa, in knock out experiments for $\mathrm{CHC}$ and caveolin-1. Additionally, the use of antibodies against clathrin or caveolin allowed us to pinpoint those cells where the respective protein expression was silenced, and thereby to understand how Pet internalization occurs in these cells. We also took advantage of the cytotoxic effects induced by Pet on the epithelial cells to correlate inhibition of internalization in silenced cells with the cytotoxic damage. Together, these approaches clearly showed that Pet is internalized by clathrin-mediated endocytosis, and they confirmed the results obtained from pharmacological studies showing that monodansylcadaverine and sucrose, but not filipin or methyl- $\beta$-cyclodextrin, inhibit Pet endocytosis. The siRNA technology for knocking out clathrin has been used successfully to study endocytic accessory proteins and receptor trafficking in epithelial cells (Hinrichsen et al., 2003).

Recognition of Pet by a putative receptor on epithelial cell membranes might induce Pet endocytosis. Inhibition of Pet effects in epithelial cells incubated at $4{ }^{\circ} \mathrm{C}$ allowed observation of Pet binding to the cell surface, and suggested that vesicular trafficking of Pet takes place inside the cells. In fact, recently we found that Pet undergoes a retrograde transport from endosomes to Golgi apparatus and endoplasmic reticulum, to be released into the cytosol after it interacts with the Sec61 translocon (Navarro-García et al., 2007); this mechanism is used by AB-type toxins (Lord et al., 2003). Interestingly, Pet is not an $A B$ toxin because: (i) it does not fit into this standard model of $\mathrm{AB}$ toxin trafficking, since it does not dissociate into component parts in the ER, but can be found in the cytosol as an intact $104 \mathrm{kDa}$ protein; (ii) the arginineoverlysine codon bias is not found in Pet; this codon bias is thought protect the translocated A chain from ubiquitindependent proteasomal degradation, since ubiquitin is appended to lysine residues (Hazes \& Read, 1997); (iii) Pet lacks a C-terminal KDEL or RDEL ER retrieval motif, so its retrograde transport to the ER may occur by a COP-1independent mechanism, such as that observed for Shiga toxin and ricin (Chen et al., 2003; Girod et al., 1999). Furthermore, transport of CT from the plasma membrane to Golgi is mainly mediated by endosomes containing caveolin-1, and is independent of clathrin-coated pits (Nichols, 2002), and it is thought that lipid rafts are needed for toxin sorting in intracellular trafficking pathways (Geny \& Popoff, 2006). However, as showed here, Pet is taken up by clathrin-dependent endocytosis, and depletion of cholesterol does not affect either its internalization or its retrograde transport. Finally, Pet-induced damage is blocked when clathrin, but not caveolin, is knocked out.

Together, these data clearly show that part of the action mechanism of Pet (the autotransporter protein secreted by EAEC) in cultured epithelial cells involves sequential steps, including binding to an unknown receptor on the cell surface, and internalization through clathrin-dependent endocytosis, which leads to intracellular trafficking and a cytosol translocation (Navarro-García et al., 2007). Finally, once in the cytosol, Pet is able to cleave targets such as $\alpha$ fodrin, which is cleaved into its calmodulin-binding domain (Canizalez-Roman \& Navarro-García, 2003), leading to cytoskeletal disruption and characteristic cell death (Navarro-García et al., 1999).

\section{ACKNOWLEDGEMENTS}

This work was supported by grants from Consejo Nacional de Ciencia y Tecnología de México (CONACYT, 30004M and C02-44660) to F. .N.-G. We thank Rocio Huerta, Lucia Chavez and Blanca Reyes for their technical help.

\section{REFERENCES}

Al-Hasani, K., Henderson, I. R., Sakellaris, H., Rajakumar, K., Grant, T., Nataro, J. P., Robins-Browne, R. \& Adler, B. (2000). The sigA gene which is borne on the she pathogenicity island of Shigella flexneri $2 \mathrm{a}$ encodes an exported cytopathic protease involved in intestinal fluid accumulation. Infect Immun 68, 2457-2463.

Bhan, M. K., Raj, P., Levine, M. M., Kaper, J. B., Bhandari, N., Srivastava, R., Kumar, R. \& Sazawal, S. (1989). Enteroaggregative Escherichia coli associated with persistent diarrhea in a cohort of rural children in India. J Infect Dis 159, 1061-1064.

Canizalez-Roman, A. \& Navarro-García, F. (2003). Fodrin CaMbinding domain cleavage by Pet from enteroaggregative Escherichia coli leads to actin cytoskeletal disruption. Mol Microbiol 48, 947-958.

Chen, A., AbuJarour, R. J. \& Draper, R. K. (2003). Evidence that the transport of ricin to the cytoplasm is independent of both Rab6A and COPI. J Cell Sci 116, 3503-3510.

Conner, S. D. \& Schmid, S. L. (2003). Regulated portals of entry into the cell. Nature 422, 37-44.

Cravioto, A., Tello, A., Navarro, A., Ruiz, J., Villafan, H., Uribe, F. \& Eslava, C. (1991). Association of Escherichia coli HEp-2 adherence patterns with type and duration of diarrhoea. Lancet 337, 262-264.

Djafari, S., Ebel, F., Deibel, C., Kramer, S., Hudel, M. \& Chakraborty, T. (1997). Characterization of an exported protease from Shiga toxinproducing Escherichia coli. Mol Microbiol 25, 771-784.

Eslava, C., Villaseca, J., Morales, R., Navarro, A. \& Cravioto, A. (1993). Identification of a protein with toxigenic activity produced by enteroaggregative Escherichia coli. In Abstracts of the 93rd General Meeting of the American Society for Microbiology, pp. 44. Washington, DC: American Society for Microbiology.

Eslava, C., Navarro-Garcia, F., Czeczulin, J. R., Henderson, I. R., Cravioto, A. \& Nataro, J. P. (1998). Pet, an autotransporter enterotoxin from enteroaggregative Escherichia coli. Infect Immun 66, 3155-3163.

Falnes, P. O. \& Sandvig, K. (2000). Penetration of protein toxins into cells. Curr Opin Cell Biol 12, 407-413.

Geny, B. \& Popoff, M. R. (2006). Bacterial protein toxins and lipids: role in toxin targeting and activity. Biol Cell 98, 633-651.

Girod, A., Storrie, B., Simpson, J. C., Johannes, L., Goud, B., Roberts, L. M., Lord, J. M., Nilsson, T. \& Pepperkok, R. (1999). Evidence for a COP-I-independent transport route from the Golgi complex to the endoplasmic reticulum. Nat Cell Biol 1, 423-430.

Harrington, S. M., Dudley, E. G. \& Nataro, J. P. (2006). Pathogenesis of enteroaggregative Escherichia coli infection. FEMS Microbiol Lett 254, $12-18$. 
Hazes, B. \& Read, R. J. (1997). Accumulating evidence suggests that several $\mathrm{AB}$ toxins subvert the endoplasmic reticulum-associated protein degradation pathway to enter target cells. Biochemistry 36, 11051-11054.

Henderson, I. R., Hicks, S., Navarro-García, F., Elias, W. P., Philips, A. D. \& Nataro, J. P. (1999). Involvement of the enteroaggregative Escherichia coli plasmid-encoded toxin in causing human intestinal damage. Infect Immun 67, 5338-5344.

Henderson, I. R., Navarro-García, F., Desvaux, M., Fernandez, R. C. \& Ala'Aldeen, D. (2004). Type V protein secretion pathway: the autotransporter story. Microbiol Mol Biol Rev 68, 692-744.

Hinrichsen, L., Harborth, J., Andrees, L., Weber, K. \& Ungewickell, E. J. (2003). Effect of clathrin heavy chain- and alpha-adaptin-specific small inhibitory RNAs on endocytic accessory proteins and receptor trafficking in HeLa cells. J Biol Chem 278, 45160-45170.

Khine, A. A. \& Lingwood, C. A. (1994). Capping and receptormediated endocytosis of cell-bound verotoxin (Shiga-like toxin). 1: Chemical identification of an amino acid in the B subunit necessary for efficient receptor glycolipid binding and cellular internalization. $J$ Cell Physiol 161, 319-332.

Lamaze, C. \& Schmid, S. L. (1995). The emergence of clathrinindependent pinocytic pathways. Curr Opin Cell Biol 7, 573-580.

Lord, J. M., Deeks, E., Marsden, C. J., Moore, K., Pateman, C., Smith, D. C., Spooner, R. A., Watson, P. \& Roberts, L. M. (2003). Retrograde transport of toxins across the endoplasmic reticulum membrane. Biochem Soc Trans 31, 1260-1262.

Maroncle, N. M., Sivick, K. E., Brady, R., Stokes, F. E. \& Mobley, H. L. (2006). Protease activity, secretion, cell entry, cytotoxicity, and cellular targets of secreted autotransporter toxin of uropathogenic Escherichia coli. Infect Immun 74, 6124-6134.

Mellman, I. (1996). Membranes and sorting. Curr Opin Cell Biol 8, 497-498.

Morris, R. E., Manhart, M. D. \& Saelinger, C. B. (1983). Receptormediated entry of Pseudomonas toxin: methylamine blocks clustering step. Infect Immun 40, 806-811.

Moya, M., Dautry-Varsat, A., Goud, B., Louvard, D. \& Boquet, P. (1985). Inhibition of coated pit formation in Hep2 cells blocks the cytotoxicity of diphtheria toxin but not that of ricin toxin. J Cell Biol 101, 548-559.

Nataro, J. P., Deng, Y., Cookson, S., Cravioto, A., Savarino, S. J., Guers, L. D., Levine, M. M. \& Tacket, C. O. (1995). Heterogeneity of enteroaggregative Escherichia coli virulence demonstrated in volunteers. J Infect Dis 171, 465-468.

Navarro-García, F., Eslava, C., Villaseca, J. M., Lopez-Revilla, R., Czeczulin, J. R., Srinivas, S., Nataro, J. P. \& Cravioto, A. (1998). In vitro effects of a high-molecular-weight heat-labile enterotoxin from enteroaggregative Escherichia coli. Infect Immun 66, 3149-3154.
Navarro-García, F., Sears, C., Eslava, C., Cravioto, A. \& Nataro, J. P. (1999). Cytoskeletal effects induced by pet, the serine protease enterotoxin of enteroaggregative Escherichia coli. Infect Immun 67, $2184-2192$.

Navarro-García, F., Canizalez-Roman, A., Luna, J., Sears, C. \& Nataro, J. P. (2001). Plasmid-encoded toxin of enteroaggregative Escherichia coli is internalized by epithelial cells. Infect Immun 69, 1053-1060.

Navarro-García, F., Canizalez-Roman, A., Burlingame, K. E., Teter, K. \& Vidal, J. E. (2007). Pet, a non- $A B$ toxin, is transported and translocated into epithelial cells by a retrograde trafficking pathway. Infect Immun 75, 2101-2109.

Nichols, B. J. (2002). A distinct class of endosome mediates clathrinindependent endocytosis to the Golgi complex. Nat Cell Biol 4, 374-378.

Saelinger, C. B., Morris, R. E. \& Foertsch, G. (1985). Trafficking of Pseudomonas exotoxin A in mammalian cells. Eur J Clin Microbiol 4, 170-174.

Sandvig, K., Olsnes, S., Brown, J. E., Petersen, O. W. \& van Deurs, B. (1989). Endocytosis from coated pits of Shiga toxin: a glycolipidbinding protein from Shigella dysenteriae 1. J Cell Biol 108, 1331-1343.

Shogomori, H. \& Futerman, A. H. (2001). Cholera toxin is found in detergent-insoluble rafts/domains at the cell surface of hippocampal neurons but is internalized via a raft-independent mechanism. J Biol Chem 276, 9182-9188.

Simons, K. \& Ikonen, E. (1997). Functional rafts in cell membranes. Nature 387, 569-572.

Steinman, R. M. \& Swanson, J. (1995). The endocytic activity of dendritic cells. J Exp Med 182, 283-288.

Tebar, F., Bohlander, S. K. \& Sorkin, A. (1999). Clathrin assembly lymphoid myeloid leukemia (CALM) protein: localization in endocytic-coated pits, interactions with clathrin, and the impact of overexpression on clathrin-mediated traffic. Mol Biol Cell 10, 2687-2702.

Torgersen, M. L., Skretting, G., van Deurs, B. \& Sandvig, K. (2001). Internalization of cholera toxin by different endocytic mechanisms. $J$ Cell Sci 114, 3737-3747.

Towbin, H., Staehelin, T. \& Gordon, J. (1979). Electrophoretic transfer of proteins from polyacrylamide gels to nitrocellulose sheets: procedure and some applications. Proc Natl Acad Sci U S A 76, 4350-4354.

Tzipori, S., Montanaro, J., Robins-Browne, R. M., Vial, P., Gibson, R. \& Levine, M. M. (1992). Studies with enteroaggregative Escherichia coli in the gnotobiotic piglet gastroenteritis model. Infect Immun 60, 5302-5306.

Edited by: I. R. Henderson 